\title{
Cardiac performance in Salmo salar with infectious salmon anaemia (ISA): putative role of nitric oxide
}

\author{
Alfonsina Gattuso ${ }^{1}$, Rosa Mazza ${ }^{1}$, Sandra Imbrogno ${ }^{1}$, Anne Sverdrup ${ }^{2}$, \\ Bruno Tota ${ }^{1,3, *}$, Are Nylund ${ }^{2}$
}

\author{
${ }^{1}$ Department of Cell Biology, University of Calabria, 87030 Arcavacata di Rende (CS), Italy \\ ${ }^{2}$ Department of Fisheries and Marine Biology, University of Bergen, 5020 Bergen, Norway \\ ${ }^{3}$ Zoological Station ‘A. Dohrn of Naples', Villa Communale, 80121 Naples, Italy
}

\begin{abstract}
Infectious salmon anaemia (ISA) is a viral disease which targets the vascular and endocardial endothelial cells. An in vitro preparation of the spontaneously beating working heart of Salmo salar L. (i.e. able to generate physiological values of output pressure, cardiac output, ventricle work and power) was used to study cardiac performance under basal (i.e. in the absence of stimuli) and loading (i.e. Frank-Starling response) conditions in both control and ISAV-affected fish. In contrast to control fish, the heart preparations of the infected counterparts showed an impairment of the FrankStarling response, particularly evident in fish infected with a higher virus dose. The Frank-Starling response was progressively impaired with the progression of the viral disease from the time of the virus administration until the 20th day. The potential involvement of nitric oxide (NO) in cardiac dysfunction was investigated by using the authentic nitric oxide synthase (NOS) substrate L-arginine and the NOS inhibitors L-NMMA and L-NIL. In contrast to control fish, infected hearts were particularly sensitive to the inducible nitric oxide synthase (iNOS) inhibitor L-NIL and insensitive to L-arginine. While pretreatment with NOS inhibitors reduced the Frank-Starling response in control hearts, it restored this response in infected counterparts. Taken together, the results indicate that cardiac dysfunction and the NO-transduction-pathway can be mechanistically linked in infected salmon.
\end{abstract}

KEY WORDS: ISA virus $\cdot$ Salmon $\cdot$ Heart $\cdot$ Nitric oxide $\cdot$ Myocardial dysfunction Resale or republication not permitted without written consent of the publisher

\section{INTRODUCTION}

Infectious salmon anaemia (ISA) is a viral disease and was first diagnosed in farmed Atlantic salmon, Salmo salar L., in Norway (Thorud \& Djupvik 1988); later it was shown that the virus could replicate in trout (Salmo trutta and Onchorhynchus mykiss) (Nylund et al. 1994, 1995, 1997, Nylund \& Jakobsen 1995, Rolland \& Nylund 1998, Snow et al. 2001) and char (Snow et al. 2001). ISA has also been reported from farmed Atlantic salmon in Scotland, Canada, the Faroe Islands and the USA (Mullins et al. 1998, Rodger et al. 1998, Bouchard et al. 2001). The viral agent is an enveloped, negative-

${ }^{*}$ Corresponding author. E-mail: tota@unical.it stranded, RNA virus closely resembling orthomyxoviruses (Falk et al. 1997, Koren \& Nylund 1997, Mjaaland et al. 1997, Krøssoy et al. 1999). ISA is characterised by several haematological abnormalities including severe anaemia, ascites, congestion and enlargement of the liver and spleen, congestion in the intestinal mucosa, petechiae in the visceral fat, and high mortality (Koren \& Nylund 1997). However, the ISA virus may also be present without causing any mortality in salmon (Nylund pers.obs.) or may cause a different pathology (Jones et al. 1999).

Vascular endothelial (Ev) and endocardial endothelium (EE) cells, lining the inner wall of the blood vessels and the luminal wall of the cardiac chambers, respectively, are target cells for the ISA virus (Nylund et al. 1995). However, budding of intact virus particles 
from polymorphonuclear leukocytes shows that these cells may also be target cells (Nylund et al. 1995). In these cell types, which are metabolically active and capable of phagocytosis, the ISA virus is able to replicate. Indeed, from these cells the virus particles can frequently be observed budding in the lumen of the heart and the blood vessels (Nylund et al. 1995, 1996).

The autocrine-paracrine function of the Ev and EE, which involves the synthesis and release of nitric oxide (NO), in addition to endothelin, prostacyclin and other autacoids, is well recognised. In particular, Ev and EE, in addition to cardiomyocytes, blood platelets, and other cell types, represent the predominant source of one of the 3 NOS isoforms, the 'endothelial' NOS (eNOS), so named as it is isolated, purified and cloned from the vascular endothelium (see e.g. Andries et al. 1998, Busse \& Fleming 2000). The expression and the activity of this isoform, with the consequent production of NO, plays a major role in controlling various functions of the peripheral vasculature (Busse \& Fleming 2000) and the heart (Balligand 2000). After induction by inflammatory and immunologic stimuli, including a diversity of infectious agents, the Ev and EE, like most cell types such as macrophages, cardiac myocytes, vascular smooth muscle cells, glial cells (to name only a few), express also another NOS isoform, the 'inducible' NOS (iNOS), whose hallmark is the high-output path of NO production. The increased generation of NO has the potential to cause tissue and organ damage through a variety of mechanisms (see review by Vallance et al. 2000). In salmonids, the presence of the L-arginine/ NO pathway and iNOS activity have been demonstrated by biochemical, immunohistochemical and immunoblotting evidence (Barroso et al. 2000), while the iNOS transcript expression has been detected in the gills after injection challenge with the Gram-positive pathogen Renibacterium salmoninarum (CamposPerez et al. 2000). In the in vitro working heart of Anguilla anguilla, it has been shown that NO plays an important role in the modulation of cardiac performance (Imbrogno et al. 2001).

Given the autocrine-paracrine role of the endothelium, the question arises as to whether Ev and EE cellshutdown caused by the ISA virus (Nylund et al. 1995) may affect cardiac function in infected salmon. In this connection, an important aspect is related to the physiological and pathophysiological roles of $\mathrm{NO}$ in the regulation of cardiac performance. In fact, depressed myocardial performance, documented in mammals during sepsis or exposure to bacterial or viral agents (Parrillo 1993), has been related specifically to the actions of cytokines and the concomitant release of higher amounts of NO (Finkel et al. 1992, Nathan 1997).
In this study we used an in vitro working-heart preparation, generating physiological values of output pressure, cardiac output, and ventricle work and power, to analyse basal cardiac performance (constant preload and afterload) and preload-induced rises in cardiac output at constant afterload (i.e. Frank-Starling response) in Atlantic salmon affected by ISAV. We used small fish in which the compact ventricular layer and the coronary vasculature are poorly developed so that cardiac function could be assessed without the variable influences of coronary circulation and the confounding paracrine effects of the vascular endothelium. We found that in comparison with control individuals, the cardiac function was impaired in infected salmon and we characterised the chronology of this impairment from the time of virus administration to the time of appearance of the typical pathological features at the peak of the disease. The involvement of NO was investigated by using the authentic NO donor L-arginine and the NOS inhibitors L-NMMA and L-NIL. The results were consistent with the hypothesis that, in infected fish, cardiac dysfunction is related to an early impairment of the NO-signalling pathway.

\section{MATERIALS AND METHODS}

Animals. The study was conducted on 144 specimens of Salmo salar ( $\mathrm{n}=40$ from the control group and $\mathrm{n}=104$ from the infected group, weight $118.17 \pm 2.88 \mathrm{~g}$, length $21.57 \pm 0.2 \mathrm{~cm}$, mean \pm SEM) supplied by a hatchery (with no history of disease) close to Bergen, Norway. The fish were kept in tanks with circulating sea water at $10^{\circ} \mathrm{C}$ at the Department of Fisheries and Marine Biology (HIB), University of Bergen (Norway). Experiments were carried out at $10 \pm 2{ }^{\circ} \mathrm{C}$.

Isolated and perfused working-heart preparation. The salmon were killed by a sharp blow to the head followed by spinectomy, and were opened ventrally behind the pectoral fins. The heart was removed without the pericardium and placed in a dish of saline for cannulation. Two cannulae were inserted, one in the ventral aorta (output) and the other in the sinus venosus (input). Isolation time was 15 to $20 \mathrm{~min}$. The cannulated heart was transferred to a perfusion chamber filled with saline and connected with a perfusion apparatus as described by Tota et al. (1991). The heart received saline from an input reservoir and pumped against an afterload pressure dictated by the height of an output reservoir. The mean input pressure (preload) was regulated in order to obtain a physiological cardiac output by varying the height of the input reservoir.

The saline composition in mmol $\mathrm{l}^{-1}$ was: $110 \mathrm{NaCl}_{\text {; }}$ $4.8 \mathrm{KCl}_{i} 1.5 \mathrm{CaCl}_{2} \cdot 2 \mathrm{H}_{2} \mathrm{O} ; 15 \mathrm{NaHCO}_{3} ; 2.5 \mathrm{NaH}_{2} \mathrm{PO}_{4}$. 
$\mathrm{H}_{2} \mathrm{O} ; 1.25 \mathrm{MgSO}_{4} \cdot 7 \mathrm{H}_{2} \mathrm{O} ; 5.55$ glucose $\cdot \mathrm{H}_{2} \mathrm{O}$; pH was adjusted to $7.5-7.65$ by adding $\mathrm{NaOH}(1 \mathrm{~N})$. The saline was equilibrated with $95 \% \mathrm{O}_{2}$ and $5 \% \mathrm{CO}_{2}$ (Sverdrup \& Helle 1994).

Measurements and calculations. Pressure was measured through T-tubes placed immediately before the input cannula and after the output cannula, using one MP-20D pressure transducer (Micron Instruments), and was connected to a Unirecord 7050 (Ugo Basile).

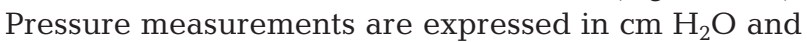
have been corrected for cannula resistance. The heart rate was calculated from pressure recording curves. The cardiac output was collected over 1 min and weighed; values were corrected for fluid density and expressed as volume measurements. The afterload (mean aortic pressure) was calculated as two-thirds diastolic pressure plus one-third maximum pressure. Stroke volume, SV (= cardiac output/heart rate) was used as a measure of ventricular performance, and recorded in $\mathrm{ml} \mathrm{kg}^{-1}$; changes in stroke volume were considered inotropic effects. Cardiac output and stroke volume were normalized per kilogramme of wet body weight. Ventricular stroke work, SW (= afterload-preload stroke volume/ventricle weight) served as an index of systolic functionality, and was measured in $\mathrm{mJ} \mathrm{g}^{-1}$.

Experimental protocols. Virus doses, feeding, basal conditions and cardiac analyses were as follows:

Challenge protocol and virus doses: The ISA virus used in the challenge was collected from infected Atlantic salmon Salmo salar in fish farms outside Bergen. The blood was stored at $-80^{\circ} \mathrm{C}$ before it was sonicated and sterile-filtered $(0.2 \mu \mathrm{m})$. The filtrate was diluted in Hanks' balanced salt solution (HBSS; Nylund et al. 1995). Two different dilutions of the filtrate: 1:1 ('higher' dose) and 1:3 ('lower' dose) were used to challenge 2 stocks of salmon. The virus titre was $0.510^{6}$ for the $1: 1$ dilution and $0.2510^{6}$ for the 1:3 dilution. The titration of ISA virus (ISAV) was performed as described by Falk et al. (1998). In the challenge experiments, each fish received an intraperitoneal injection of $0.2 \mathrm{ml}$ virus solution, while each control fish received an intraperitoneal injection of $0.2 \mathrm{ml}$ HBSS. The different stocks were kept in separate tanks. Before injection, the fish were anaesthetized with metacain (MS222). For each control and infected sample, measurements of weight and length were made and for each infected fish clinical signs of disease were noted. Haematocrit measurements, as an index of progression of infection, were made in the infected fish and compared with measurements of control fish.

Feeding status: The fish were fed 3 times a day ad libitum, i.e. they were kept under normal feeding conditions. Except for those entering the terminal stage, we did not detect any weight differences between the control fish and ISAV-infected salmon at any time during the challenge experiments.

Fish groups: Three stocks of salmon were used for the functional studies, i.e. 1 control group and 2 groups of fish infected by the 'higher' and 'lower' virus dose, respectively. The infected fish were analyzed on the basis of the number of days after challenge in order to determine the chronology of cardiac impairment. Infected fish of both groups were examined from the 8th until the 23th day from the beginning of infection, divided into 4 periods: I (Days 8 to 11), II (Days 12 to 15), III (Days 16 to 19) and IV (Days 20 to 23).

Basal conditions: Isolated perfused hearts were allowed to equilibrate to conditions simulating an in vivo resting state for up to 15 to $20 \mathrm{~min}$. In all experiments the diastolic afterload-pressure was set at about $30 \mathrm{~cm} \mathrm{H}_{2} \mathrm{O}$ and the input pressure was regulated to obtain a cardiac output of about 15 to $20 \mathrm{ml} \mathrm{min}^{-1} \mathrm{~kg}^{-1}$ (wet body weight). The heart generated its own rhythm. Cardiac output, heart rate and aortic pressure were measured simultaneously during the experiments. Hearts that did not stabilise within 15 to $20 \mathrm{~min}$ from the onset of perfusion were discarded.

Drug application: After the 15 to 20 min control period, the treated hearts were perfused for $20 \mathrm{~min}$ with saline enriched with isoproterenol, L-arginine, $\mathrm{N}^{\mathrm{G}}$-monomethyl-L-arginine (L-NMMA), L- $\mathrm{N}^{6}$-(1-iminoethyl)lysyne (L-NIL). Each heart was tested with 1 concentration of the drug.

Frank-Starling response in control and treated hearts: These experiments were designed to analyse the intrinsic mechanical characteristics of the heart preparation in both control and infected fish. We determined the Frank-Starling response of the heart by examining the effects of increasing filling pressure on cardiac output (CO) and stroke volume (SV). To define the maximum $\mathrm{CO}$ of the heart preparation, after the stabilization period (15 to $20 \mathrm{~min}$ ), starting from basal conditions, filling pressure was increased until there was no further discernible increase in $\mathrm{CO}$. For each filling pressure increase, the variables of cardiac performance were measured after 10 min perfusion with saline. The range of preload used was from $1.05 \pm 0.28$ to $4.45 \pm 0.14 \mathrm{~cm} \mathrm{H}_{2} \mathrm{O}$. Each increment was $0.5 \mathrm{~cm}$ $\mathrm{H}_{2} \mathrm{O}$. The output pressure was stable at $30 \mathrm{~cm} \mathrm{H}_{2} \mathrm{O}$.

In the treated hearts, after stabilisation and the perfusion with the NOS inhibitors, the filling pressure was increased in accordance with the procedures used for the Starling curves of the control group.

Statistics. The results are expressed as means $( \pm$ SEM). Each heart received only 1 concentration of the drug being tested, under control conditions. Since each heart represented its own control, the statistical significance of differences was assessed on parameter 
changes using a paired Student's $t$-test $(\mathrm{p}<0.05)$. Percent changes were evaluated as the mean \pm SEM of the percent changes observed in individual experiments.

Drugs and chemicals. All the solutions were prepared in double-distilled water; dilutions were made in Ringer's solution just before use. L-NMMA ( $\mathrm{N}^{\mathrm{G}}$-monomethyl-L-arginine), L-NIL (L- $\mathrm{N}^{6}$-(1-iminoethyl)lysyne), L-arginine, L-lysine and isoproterenol were purchased from Sigma Chemical Company.

\section{RESULTS}

\section{Infected fish}

Control and infected salmon were kept for about $30 \mathrm{~d}$ in separate tanks. In the challenged fish, the first clinical signs occurred about $15 \mathrm{~d}$ after virus injection and included darkening of the skin, abdominal distension, occasional exophthalmia and reduction of mobility. Weight loss was never observed in infected salmon.

When the first signs of the disease become evident, the haematocrit values (independent of the virus dose used) were about $10-15 \%$ in contrast to $35-40 \%$ in control fish.

No differences in the cardiac weights between control and infected fish were observed. The ISA infection did not alter the mass of heart/ventricle relative to body mass.

\section{Isolated working-heart preparations}

The haemodynamic characteristics of the preparations were consistent with the mechanical performance of the salmonid heart (Graham \& Farrell 1989). Baseline cardiac parameters are listed in Table 1.

Preliminary time-course experiments indicated that the performance of both control and infected hearts was stable for more than $2 \mathrm{~h}$ (data not shown) and, on the basis of this profile, all the following experiments were carried out within this period.
The intrinsic mechanical characteristics of the heart preparation were characterised on the basis of the Frank-Starling response. Starling curves were generated in the range of loads used by changing the input pressure. For the cardiac preparations from control fish, the curves showed that with increasing preload, a significant increase in cardiac output (CO) and stroke volume (SV), an index of contractility, occurred (Fig. 1); heart rate (HR) was independent of preload, so that the increases in cardiac output reflected those of stroke volume. Maximum cardiac output was $50 \pm 6.55 \mathrm{ml}$ $\mathrm{min}^{-1} \mathrm{~kg}^{-1}$ body mass, and maximum stroke volume was $0.69 \pm 0.05 \mathrm{ml} \mathrm{kg}^{-1}$ body mass, obtained with an input pressure of $4.14 \pm 0.25 \mathrm{~cm} \mathrm{H}_{2} \mathrm{O}$. These results were in agreement with the Starling response described in salmonids (Graham \& Farrell 1989) and confirmed the general view that in the teleost heart, stroke volume is very sensitive to filling pressures (Farrell \& Jones 1992).

In contrast to the control fish, the challenged heart preparations were characterised by an impairment of the Frank-Starling response; this was particularly dramatic in the preparations infected with the higher virus dose. In addition, we observed that deterioration of the Starling response increased with the progression of the infection and increased virus dose. At the lower dose, the preparations from control group and infected fish of Periods I and II complied with the Frank-Starling law (i.e. $\mathrm{CO}$ and $\mathrm{SV}$ increased significantly parallel to increasing filling pressure); in Period III fish, a significant response was observed only in the first 3 increments of the preload; subsequent increases in filling pressure had no significant effects on CO and SV. In contrast, at the higher dose, starting from the second period of infection, the hearts failed to respond to increasing preload (Fig.1).

Treatment with the synthetic cathecolamine, isoproterenol, in a range of concentrations from $10^{-8} \mathrm{M}$ to $10^{-6} \mathrm{M}$, induced an increase in heart rate (not significant) without a correspondent increase in cardiac output and peak pressure (pulse) in control fish. In the challenged fish (at the higher dose of virus), a signifi-

Table 1. Salmo salar. Performance parameters (means \pm SEM) under basal conditions in control salmon and salmon infected with ISA. HR: heart rate; CO: cardiac output; SV: stroke volume; SW: stroke work; Periods I-IV: 8-11 d, 12-15 d, 16-19 d and 20-23 d from infection, respectively

\begin{tabular}{|lcccrrr|}
\hline Condition & $\begin{array}{c}\mathrm{HR} \\
\left(\text { beats } \mathrm{min}^{-1}\right)\end{array}$ & $\begin{array}{c}\text { Filling pressure } \\
\left(\mathrm{cm} \mathrm{H}_{2} \mathrm{O}\right)\end{array}$ & $\begin{array}{c}\text { Output pressure } \\
\left(\mathrm{cm} \mathrm{H}_{2} \mathrm{O}\right)\end{array}$ & $\begin{array}{c}\mathrm{CO} \\
\left(\mathrm{ml} \mathrm{min}^{-1} \mathrm{~kg}^{-1}\right)\end{array}$ & $\begin{array}{c}\mathrm{SV} \\
\left(\mathrm{ml} \mathrm{kg}^{-1}\right)\end{array}$ & $\begin{array}{c}\mathrm{SW} \\
\left(\mathrm{mJ} \mathrm{g}^{-1}\right)\end{array}$ \\
\hline Control & $66.48 \pm 1.26$ & $1.05 \pm 0.28$ & $28.19 \pm 0.22$ & $18.99 \pm 0.47$ & $0.29 \pm 0.13$ & $1.09 \pm 0.09$ \\
Period I & $66.42 \pm 0.87$ & $1.13 \pm 0.85$ & $27.23 \pm 0.62$ & $16.93 \pm 0.81$ & $0.27 \pm 0.13$ & $0.8 \pm 0.17$ \\
Period II & $62.95 \pm 0.45$ & $1.22 \pm 0.32$ & $27.21 \pm 0.45$ & $15.55 \pm 0.54$ & $0.25 \pm 0.04$ & $0.72 \pm 0.06$ \\
Period III & $62.51 \pm 2.01$ & $0.89 \pm 0.3$ & $28.57 \pm 0.69$ & $16.54 \pm 0.57$ & $0.27 \pm 0.12$ & $0.93 \pm 0.08$ \\
Period IV & $63.41 \pm 0.59$ & $0.85 \pm 0.37$ & $27.8 \pm 0.12$ & $19.21 \pm 0.41$ & $0.3 \pm 0.08$ & $0.9 \pm 0.14$ \\
\hline
\end{tabular}




\section{LOWER DOSE}
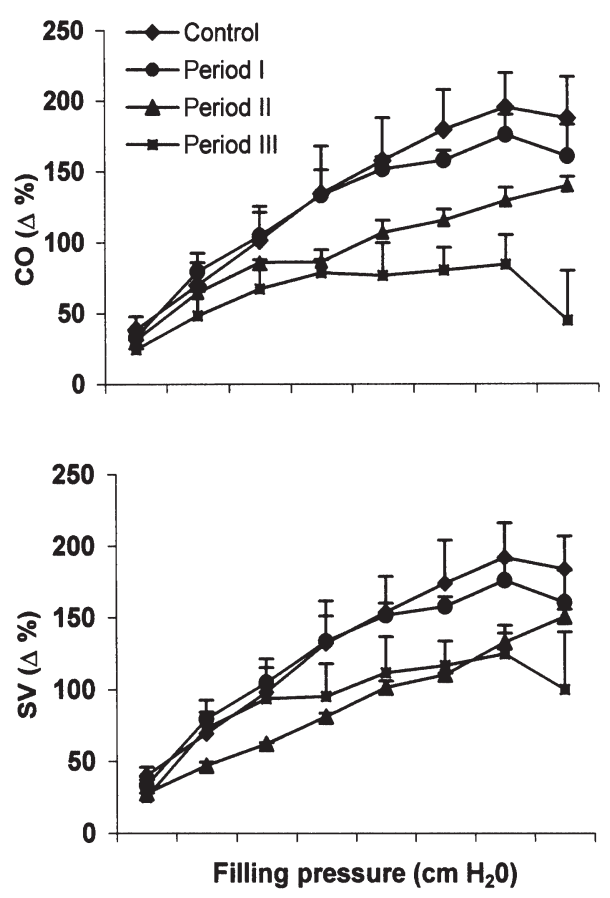

HIGHER DOSE
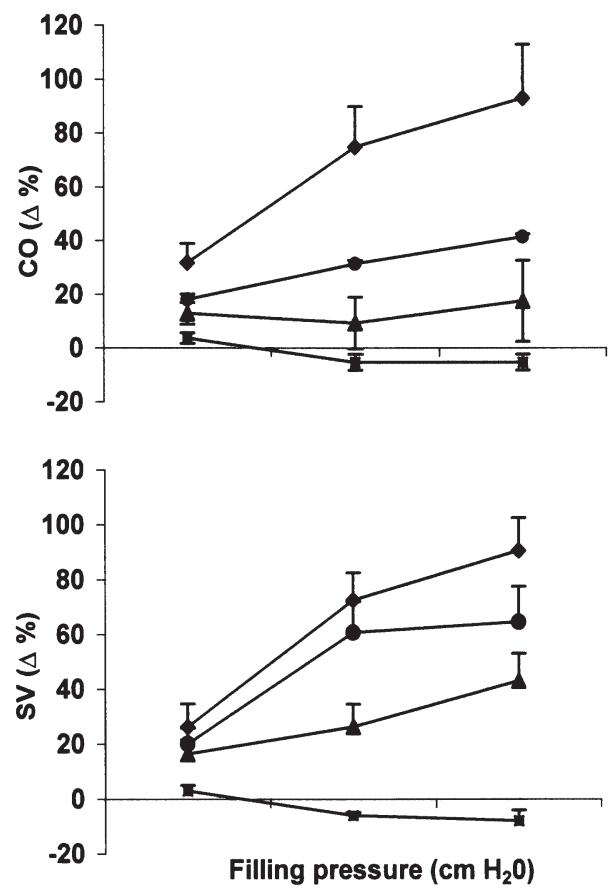

Fig. 1. Salmo salar. Cardiac output $(\mathrm{CO})$ and stroke volume (SV) responses to increased filling pressure in control and infected fish at lower and higher viral doses. Periods I, II, III = 8-11 d, 12-15 d and 16-19 d from infection, respectively. Each increment is $0.5 \mathrm{~cm}$ $\mathrm{H}_{2} \mathrm{O}$. Preload ranged from $1.05 \pm 0.28$ to $4.45 \pm 0.14 \mathrm{~cm}$ $\mathrm{H}_{2} \mathrm{O}$. In this and in the following figures a Student's $t$-test was used for statistical analysis, with $\mathrm{n}=4$ for each group

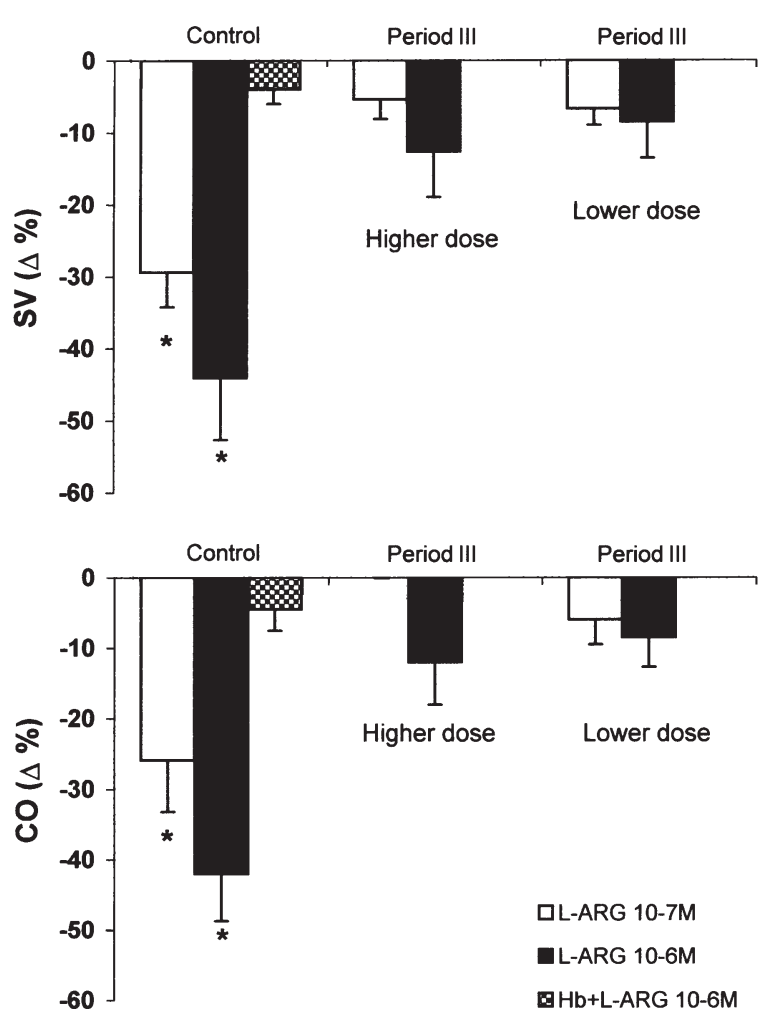

Fig. 2. Salmo salar. Effects of $10^{-7} \mathrm{M}$ and $10^{-6} \mathrm{M}$ L-arginine on $\mathrm{CO}$ and SV of control fish in presence and absence of $10^{-6} \mathrm{M}$ haemoglobin and in infected fish (Period III) at the higher and lower virus doses. * Significant difference at $\mathrm{p}<0.05$ cant increase in HR without a correspondent increase in cardiac output and peak pressure (pulse) was observed only during the first and second periods of the infection (data not shown).

\section{Effects of NO on basal cardiac performance}

To determine whether in healthy fish NO affects cardiac performance under basal conditions (i.e. in the absence of mechanical or chemical stimuli), the heart preparations were exposed to the authentic NOS substrate L-arginine $\left(10^{-7}\right.$ and $\left.10^{-6} \mathrm{M}\right)$, which induced a significant decrease in $\mathrm{CO}$ and $\mathrm{SV}$ at both concentrations (Fig. 2). These effects of L-arginine were clearly due to NO since they were counteracted by haemoglobin $\left(10^{-6} \mathrm{M}\right)$ which inactivates NO (Moncada et al. 1991) (Fig. 2). Conversely, pretreatment with L-NMMA $\left(10^{-6} \mathrm{M}\right)$, an inhibitor of eNOS, induced a significant increase in CO and SV (Fig. 3). Taken together these results indicate that in the unstimulated preparations from the control fish there was a basal nitrergic tone which exerted a mild negative inotropism. In contrast, perfusion with the specific inhibitor of iNOS, L-NIL $\left(10^{-6} \mathrm{M}\right)$ (Mayer \& Andrew 1998) had no significant effects on $\mathrm{CO}$ and SV, suggesting that the enzyme was not substantially present in the control fish (Fig. 4).

Salmon (Period III) infected with either of the infective doses were not sensitive to exposure to L-arginine 
LOWER DOSE
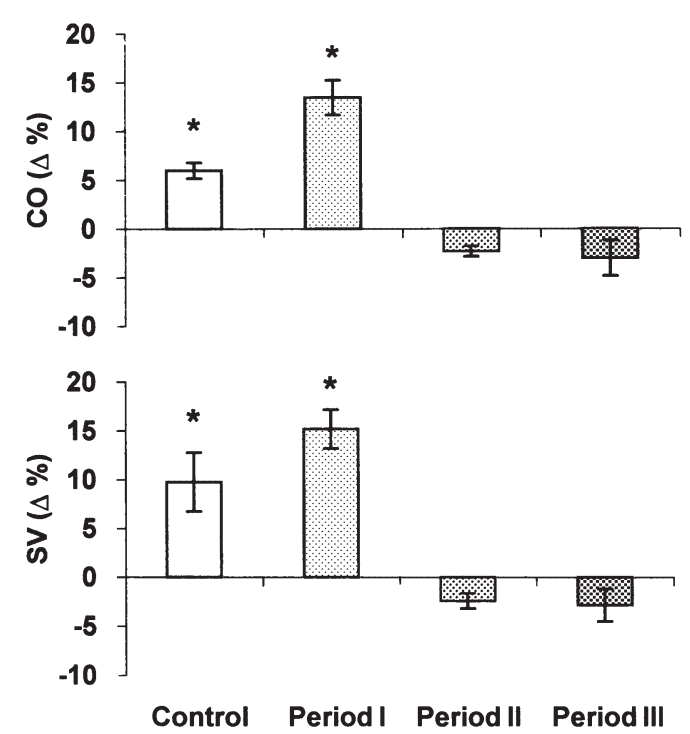

HIGHER DOSE
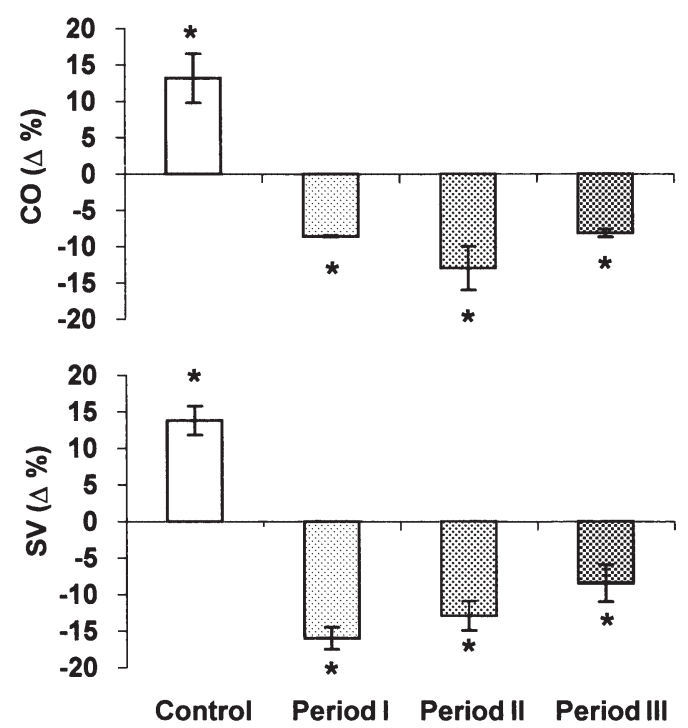

Fig. 3. Salmo salar. Effects of $10^{-6} \mathrm{M}$ L-NMMA on control and infected (Periods I-III) fish at the lower and higher virus doses. ${ }^{*}$ Significant difference at $\mathrm{p}<0.05$

$\left(10^{-7} \mathrm{M}\right.$ and $\left.10^{-6} \mathrm{M}\right)$. In fact, at these concentrations a mild but not significant reduction in $\mathrm{CO}$ and $\mathrm{SV}$ was observed (Fig. 2).

In contrast to control fish, inhibition of NOS by LNMMA $\left(10^{-6} \mathrm{M}\right)$ induced a negative effect on $\mathrm{CO}$ and $\mathrm{SV}$ in the heart preparations of each of the 3 groups of the infected fish challenged with the higher virus dose.
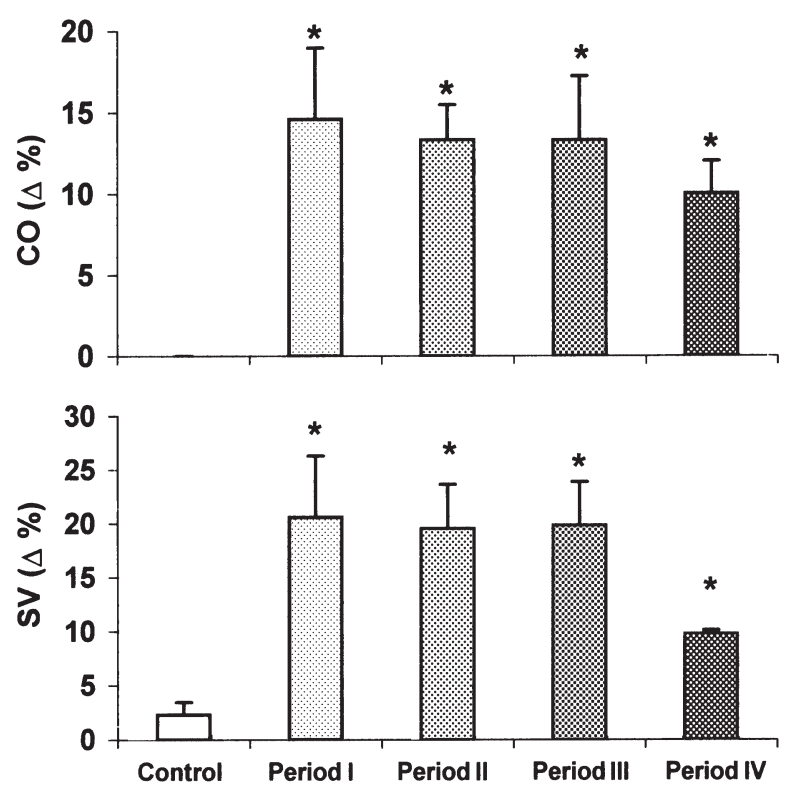

Fig. 4. Salmo salar. Effects of $10^{-6} \mathrm{M}$ L-NIL on control and infected (Periods I-IV) fish at the lower virus dose. Period IV $=20-23 \mathrm{~d}$ from infection. ${ }^{*}$ Significant difference at $\mathrm{p}<0.05$
In the preparations from lower-dose fish, Group I showed a response similar to the control, while Group II and III preparations were insensitive to the drug (Fig. 3). Preliminary experiments indicated that the effect of L-NMMA on infected fish was reversed by Larginine $\left(10^{-3} \mathrm{M}\right)$ but not by L-lysine $\left(10^{-3} \mathrm{M}\right)$ (data not shown). D-arginine is not taken up by the amino acid uptake mechanism and therefore cannot be used as a control (Amrani et al. 1992). In contrast to the controls, inhibition of iNOS with L-NIL $\left(10^{-6} \mathrm{M}\right)$ caused a significant increase in $\mathrm{CO}$ and $\mathrm{SV}$ in the hearts of each group treated at the higher dose (Fig.4).

\section{Nitric oxide and the Frank-Starling response}

To ascertain the effect of NO on Starling's resonse in the isolated and perfused heart preparations of salmon, we studied the Frank-Starling response after treatment with the NOS inhibitors L-NMMA $\left(10^{-6} \mathrm{M}\right)$ and L-NIL $\left(10^{-6} \mathrm{M}\right)$. In the control group, the FrankStarling response was notably depressed after pretreatment with the inhibitors, indicating that in the absence of a basal nitrergic tone, heart preparations are less responsive to filling pressures. In contrast, in infected fish of Period III, pretreatment with the inhibitors completely restored the Frank-Starling response. In particular, the response to L-NIL was higher than that to L-NMMA: at maximum filling pressure, $\mathrm{CO}$ increased by about $200 \%$ with L-NIL and by about $150 \%$ with L-NMMA (Fig. 5). 
L-NMMA
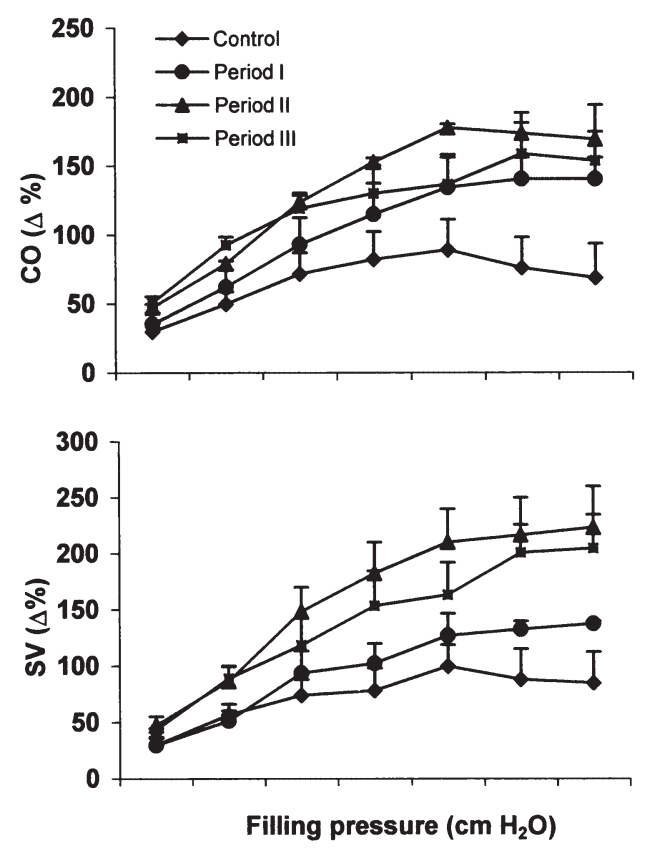
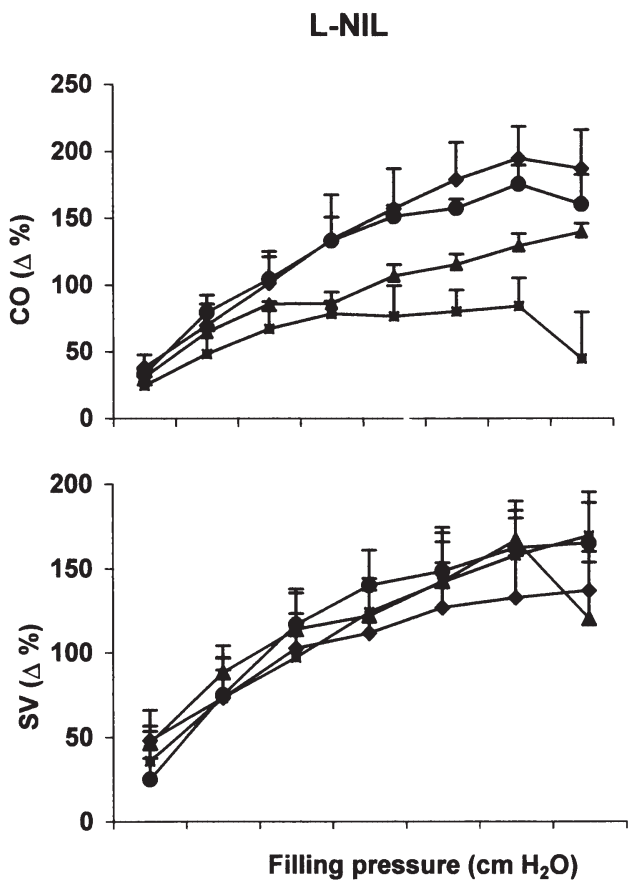

Fig. 5. Salmo salar. $\mathrm{CO}$ and SV responses to increased filling pressure in control and infected (Periods I-III) fish at the lower virus dose after treatment with $\left(10^{-6}\right.$ M) L-NMMA and $\left(10^{-6} \mathrm{M}\right)$ L-NIL. Each filling pressure increment is $0.5 \mathrm{~cm} \mathrm{H}_{2} \mathrm{O}$. Preload ranged from $1.05 \pm$ 0.28 to $4.45 \pm 0.14 \mathrm{~cm} \mathrm{H}_{2} \mathrm{O}$

\section{DISCUSSION}

\section{Isolated working-heart preparations}

The responses to loading stimuli of the in vitro preparations used in this work correspond to the haemodynamic responses reported for salmonid hearts (Graham \& Farrell 1989, Davie \& Farrell 1991). The fact that the isolated and luminally perfused working heart of Salmo salar generated physiologically comparable values of output pressure, cardiac output and ventricle work is important. In fact, mechanical stresses induce the release of cardiac autocrine-paracrine factors, including NO, that affect heart performance (Pinsky et al. 1997).

Like most fish hearts, salmon hearts are very sensitive to filling pressure (i.e. the Frank-Starling response) and this intrinsic mechanism in vivo contributes substantially to the increased cardiac output associated with exercise (Farrell \& Jones 1992). It is noteworthy that in the infected salmon, despite the absence of structural and ultrastructural pathological changes to their hearts (Nylund unpubl. data), the cardiac performance (measured as the Frank-Starling response) was progressively impaired by the viral disease, significantly so from Days 15 to 16 after infection. This finding indicates that, in this species, ISA is associated with a deterioration of the mechanical performance of the heart. It also provides the rationale for exploring the possibility that such cardiac deterioration in infected salmon could be related to the expression of iNOS upon stimulation of pro-inflammatory cytokines.

\section{Basal nitrergic tone}

Although we did not measure NO production in control and infected fish, the data obtained with the endogenous substrate of NOS (L-arginine) and the eNOS inhibitor L-NMMA indicate that in the control salmon heart an NO signal induced a mild but significant negative inotropism on the basal (i.e. unstimulated) cardiac performance. Similar results, reported for the isolated working hearts of an eel (Anguilla anguilla) (Imbrogno et al. 2001) and a frog (Rana esculenta) (Sys et al. 1997), and for several cardiac preparations from mammals (Balligand 2000), suggest that the tonic release of discrete quanta of NO, mainly associated with eNOS activity, is an important paracrine factor in the functional modulation of cardiac performance (Moncada et al. 1991). It appears that in healthy salmon there is no substantial iNOS activity, since neither CO nor SV were affected by pre-treatment with the specific inhibitor of iNOS, L-NIL. In contrast, L-NIL significantly increased $\mathrm{CO}$ and SV in cardiac preparations from fish with progressive ISA. Although iNOS activity remains to be detected in the infected hearts, their remarkable sensitivity to L-NIL could reflect increases of cardiac iNOS activity and NO generation with consequent changes in the cardiac function of infected fish. The challenged preparations also responded to L-NMMA in a different manner than control hearts. The preparations from fish infected with higher viral doses had an opposite (i.e. negative) response to the inhibitor, while the Group II and III 
hearts from the lower-dose-infected fish were insensitive to it, suggesting a relation between NO-related cardiac changes and infective dose. Interestingly, the hearts of infected fish were insensitive to L-arginine. L-arginine may become limiting and reduce formation of NO under some pathological conditions; some endothelial dysfunctions are quickly reversed by increases in extracellular L-arginine (see Ogonowski et al. 2000). An enhanced cellular L-arginine transport, concurrent with the induction of iNOS (McDonald et al. 1997), is also a possibility. Our findings suggest that administration of the substrate for NOS has no beneficial effect on cardiac dysfunction in infected fish.

\section{Nitric oxide and the Frank-Starling response}

The remarkable effects elicited by the NOS inhibitors L-NMMA and L-NIL on the filling pressure response of the cardiac preparations indicate that basal release of endogenous NO significantly influences the Frank-Starling mechanism in the working heart of healthy salmon. This result is in agreement with similar data obtained for the working heart of the eel in vitro (Imbrogno et al. 2001) and in mammalian heart preparations (Prendergast et al. 1997). Fish have a less marked chronotropic response to exercise than mammals, so that in vivo their increase in cardiac output associated with exercise relies basically on the Frank-Starling response (Farrell and Jones 1992). Conceivably, NO signalling plays a major role in the modulation of ventricular performance in the fish heart. It has been suggested that cardiac NO may act on either systolic (e.g. mechanisms involving a reduction of intracellular calcium: Méry et al. 1994, Shah et al. 1994) or diastolic (e.g. reduction in diastolic stiffness: Paulus et al. 1994) functions (see Balligand 2000 for review).

The deterioration in the Frank-Starling response in infected salmon is the first documentation in fish of an early heart dysfunction related to a viral disease. It also raises the important question of a putative role of $\mathrm{NO}$ in this cardiac pathogenesis, which is strongly suggested by the evidence that pre-treatment with NOS inhibitors dramatically restored cardiac performance in infected fish. The finding that the deterioration in the Frank-Starling response is reversible is consistent with the normal cardiac morphology of infected fish. The possibility remains that some of the 'pathological' NO may be generated by eNOS rather than iNOS, or by a combination of both isoforms. However, the greater 'beneficial' effect of the selective inhibitor iNOS, L-NIL, compared with L-NMMA which is not isoform selective, might be a consequence of targeting the 'pathological' NO whilst leaving the 'physiological'
NO unaffected. This appears similar to therapeutic strategies adopted in animal models and in humans with septic shock. In such models the induction of iNOS, following endothelial damage (Binko et al. 1999), in vivo endotoxin injection (Kelly et al. 1996), or activation of pro-inflammatory cytokines (Finkel et al. 1992) with consequent generation of large amounts of $\mathrm{NO}$, is responsible for a reversible defect in myocardial function (Vallance et al. 2000).

A note of caution: we did not analyse any parameter (e.g. cortisol) of the stress reaction nor any cytokine marker (e.g. TNF or macrophage activation) known to be activated by the infectious state, which in turn may influence NO production from various cellular sources in the diseased fish. Therefore, the NO-dependent cardiac changes in ISA salmon cannot be directly correlated with endocardial dysfunction.

In conclusion, we have shown that cardiac function, measured as the Frank-Starling response, was progressively impaired during the development of ISA in Atlantic salmon, being significant from Days 15 to 16 after the infection. The heart preparations of infected fish were particularly sensitive to the iNOS inhibitor LNIL and insensitive to L-arginine. The Frank-Starling response was sensitive to NOS inhibition in control hearts; in contrast, pretreatment with NOS inhibitors (L-NMMA and, especially, L-NIL) restored this response in infected fish.

These results support the hypothesis that ISA is an endothelial-endocardial viral disease in which impairment of the endothelium, associated with a perturbance of NO homeostasis (perhaps via iNOS), plays a major role in cardiac pathogenesis.

Acknowledgements. Access to the istallations at the University of Bergen, Norway, has been supported by the IHP (Improving Human Research Potential) Programme from the European Union through Contract No. HPRI-CT-1999-00056 'Bergen Marine Food Chain Research Infrastructure'. B.T. was supported by PNRA (Programma Nazionale di Ricerche in Antartide, 2000). The authors would like to thank Professor Karen B. Helle, Department of Physiology, University of Bergen, Norway, for valuable criticism and Mrs Clelia Booman, Administrative Coordinator of Bergen Marine Food Chain Research Infrastructure University of Bergen, Norway, for her precious help in the administrative procedures.

\section{LITERATURE CITED}

Amrani M, O'Shea J, Allen NJ, Harding SE, Jayakumar J, Pepper JR, Moncada S, Yacoub MH (1992) Role of basal release of nitric oxide on coronary flow and mechanical performance of the isolated rat heart. J Physiol 456: 681-687

Andries LJ, Brutsaert DL, Sys SU (1998) Nonuniformity of endothelial constitutive nitric oxide synthase distribution in cardiac endothelium. Circ Res 82:195-203

Balligand JL (2000) Regulation of cardiac function by nitric oxide. In: Mayer B (ed) Handbook of experimental phar- 
macology, Vol 143. Springer-Verlag, Berlin, p 206-234

Barroso JB, Carreras A, Esteban FJ, Peinado MA and 5 others (2000) Molecular and kinetic characterization and cell type location of inducible nitric oxide synthase in fish. Am J Physiol 279: R650-R656

Binko J, Meachem S, Majewski H (1999) Endothelium removal induces iNOS in rat aorta in organ culture, leading to tissue damage. Am J Physiol 276:E125-E134

Bouchard DA, Brockway K, Giray C, Keleher W, Merrill PL (2001) First report of Infectious salmon anemia (ISA) in the United States. Bull Eur Assoc Fish Pathol 21:86-88

Busse R, Fleming I (2000) Nitric oxide and regulation of vascular tone. In: Mayer B (ed) Handbook of experimental pharmacology, Vol 143. Springer-Verlag, Berlin, p 179-206

Campos-Perez JJ, Ward M, Grabowski PS, Ellis AE, Secombes CJ (2000) The gills are an important site of iNOS expression in rainbow trout Oncorhynchus mykiss after challenge with the Gram-positive pathogen Renibacterium salmoninarum. Immunology 99:153-161

Davie PS, Farrell AP (1991) Coronary perfusion of an isolated heart preparation from the dogfish (Squalus acanthias) during hypoxia. Can J Zool 69:1822-1828

Devold M, Krossøy B, Aspehaug V, Nylund A (2000) Use of RT-PCR for diagnosis of infectious salmon anaemia virus (ISAV) in carrier sea trout Salmo trutta after experimental infection. Dis Aquat Org 40:9-18

Falk K, Namork E, Rimstad E, Mjaaland S, Dannevig BH (1997) Characterization of infectious salmon anemia virus, an orthomyxo-like virus isolated from Atlantic salmon (Salmo salar L.). J Virol 71:9016-9023

Falk K, Namork E, Dannevig BH (1998) Characterization and applications of a monoclonal antibody against infectious salmon anaemia virus. Dis Aquat Org 34: 77-85

Farrell AP, Jones DR (1992) The heart. In: Hoar WS, Randall DR (eds) Fish physiology, Vol XIIA. Academic Press, Inc, p 1-88

Finkel MS, Oddis CV, Jacob TD, Watkins SC, Hattler BG, Simmons RL (1992) Negative inotropic effect of cytokines on the heart mediated by nitric oxide. Science 257: 387-389

Graham MS, Farrell AP (1989) The effect of temperature acclimation and adrenaline on the performance of a perfused trout heart. Physiol Zool 62:38-61

Imbrogno S, De Iuri L, Mazza R, Tota B (2001) Nitric oxide modulates cardiac performance in the heart of Anguilla anguilla. J Exp Biol 204:1719-1727

Jones SRM, MacKinnon AM, Groman DD (1999) Virulence and pathogenicity of infectious salmon anemia virus isolated from farmed salmon in Atlantic Canada. J Aquat Anim Health 11:400-405

Kelly RA, Balligand JL, Smith TW (1996) Nitric oxide and cardiac function. Circ Res 79:363-380

Koren CWR, Nylund A (1997) Morphology and morphogenesis of infectious salmon anaemia virus replicating in the endothelium of Atlantic salmon Salmo salar L. Dis Aquat Org 29:99-109

Krossøy B, Hordvik I, Nilsen F, Nylund A, Endresen C (1999) The putative polymerase sequence of infectious salmon anemia virus suggests a new genus within the Orthomyxoviridae. J Virol 73:2136-2142

Mayer B, Andrew P (1998) Nitric oxide synthases: catalytic function and progress towards selective inhibition. Naunyn-Schmiedebergs Arch Pharmakol 358:127-133

McDonald KK, Zharidov S, Block ER, Kilberg MS (1997) A caveolar complex between the cationic amino acid transporter 1 and endothelial nitric oxide synthase may explain the arginine paradox. J Biol Chem 272:31213-31216
Mèry P, Riou B, Chemla D, Lecarpentier Y (1994) Cardiotoxicity of colchicine in the rat. Intensive Care Med 20: 119-123

Mjaaland S, Rimstad E, Falk K, Dannevig BH (1997) Genomic characterization of the virus causing infectious salmon anemia in Atlantic salmon (Salmo salar L.): an orthomyxolike virus in a teleost. J Virol 71:7681-7686

Moncada S, Palmer RMJ, Higgs EA (1991) Nitric oxide: physiology, pathophysiology and pharmacology. Pharmacol Rev 43:109-142

Mullins JE, Groman D, Wadowska D (1998) Infectious salmon anaemia in salt water Atlantic salmon (Salmo salar L.) in New Brunswick, Canada. Bull Eur Assoc Fish Pathol 18: $110-114$

Nathan C (1997) Inducible nitric oxide synthase: What difference does it make? J Clin Investig 100:2417-2423

Nylund A, Jakobsen P (1995) Sea trout as a carrier of infectious salmon anemia virus. J Fish Biol 47:174-176

Nylund A, Alexandersen S, Løvik P, Jakobsen P (1994) The response of brown trout (Salmo trutta L.) to repeated challenge with infectious salmon anaemia (ISA). Bull Eur Assoc Fish Pathol 14:167-170

Nylund A, Hovland T, Watanabe K, Endresen C (1995) Presence of infectious salmon anaemia virus (ISAV) in different organs of Salmo salar L. collected from three fish farms. J Fish Dis 18:135-145

Nylund A, Krossøy B, Watanabe K, Holm JA (1996) Target cells for the ISA virus in Atlantic salmon (Salmo salar L.). Bull Eur Assoc Fish Pathol 16:68-72

Nylund A, Kvenseth AM, Krossøy B, Hodneland K (1997) Raimbow trout (Onchorhynchus mykiss Walbaum, 1792): a carrier of infectious salmon anemia (ISAV). J Fish Dis 20:275-279

Ogonowski AA, Kaesemeyer WH, Jin L, Ganapathy V, Leibach FH, Caldwell RW (2000) Effects of NO donors and synthase agonists on endothelial cell uptake of L-arg and superoxide production. Am J Physiol 278: C136-C143

Parrillo J (1993) Pathogenetic mechanisms of septic shock. N Engl J Med 328:1471-1477

Paulus WJ, Vantrimpont PJ, Shah AM (1994) Acute effects of nitric oxide on left ventricular relaxation and diastolic distensibility in humans. Circulation 89:2070-2078

Pinsky DJ, Patton S, Mesaros S, Brovkovych V, Kubaszewski E, Grunfeld S, Malinski T (1997) Mechanical transduction of nitric oxide synthesis in the beating heart. Circ Res 81: 372-379

Prendergast BD, Sagach VF, Shah AM (1997) Basal release of nitric oxide augments the Frank-Starling response in the isolated heart. Circulation 96:1320-1329

Rodger HD, Turnbull T, Muir F, Millar S, Richards RH (1998) Infectious salmon anaemia (ISA) in the United Kingdom. Bull Eur Assoc Fish Pathol 18:115-116

Rolland JB, Nylund A (1998) Sea running trout: carrier and transmitter of the infectious salmon anemia virus (ISAV). Bull Eur Assoc Fish Pathol 18(2):1-6

Shah AM, Spurgeon HA, Sollott SJ, Talo A, Lakatta EG (1994) 8-bromo-cGMP reduces the myofilament response to $\mathrm{Ca}^{2+}$ in intact cardiac myocytes. Circ Res 74:970-978

Snow M, Raynard RS, Bruno DW (2001) Comparative susceptibility of Artic char (Salvelinus alpinus), rainbow trout (Oncorhynchus mykiss) and brown trout (Salmo trutta) to the Scottish isolate of infectious salmon anaemia virus. Aquaculture $196: 47-54$

Sverdrup A, Helle KB (1994) Differential patterns of relaxation by atrial natriuretic peptide in major blood vessels of two distantly related teleosts. Regul Pept 53:89-101

Sys SU, Pellegrino D, Mazza R, Gattuso A, Andries LJ, Tota B (1997) Endocardial endothelium in the avascular heart of 
the frog: morphology and role of nitric oxide. J Exp Biol 200:3109-3118

Thorud K, Djupvik HO (1988) Infectious anaemia in Atlantic salmon (Salmo salar L.). Bull Eur Assoc Fish Pathol 8: 109-111

Tota B, Acierno R, Agnisola C (1991) Mechanical performance of the isolated and perfused heart of the haemoglo-

Editorial responsibility: Jo-Ann Leong,

Corvallis, Oregon, USA binless Antartic icefish Chionodraco hamatus (Lonnberg): effects of loading conditions and temperature. Phil Trans R Soc Lond B Biol Sci 332:191-198

Vallance P, Rees D, Moncada S (2000) In: Mayer B (ed) Therapeutic potential of NOS inhibitors in septic shock. Handbook of experimental pharmacology, Vol 143. SpringerVerlag, Berlin, p 385-397

Submitted: July 11, 2001; Accepted: April 26, 2002 Proofs received from author(s): September 17, 2002 